\title{
OUR EXPERIENCE TO DISCOVER THE ESSENCE OF PEDAGOGICAL FACILITATION
}

\begin{abstract}
Today, the changes of the education system conditioned by the new strategy of education are aimed not only at the modernization of the content and methodological tools of education but also at the reconstruction of the whole characteristic/structure/ of the subject implementing those changes. In this article, we have tried to present pedagogical facilitation in the context of modern education, the requirements for a pedagogue who has mastered the technology of facilitation, the content of the pedagogue-facilitator activity, and the research carried out in two stages reveals how the image of the facilitator-teacher is perceived in the students' consciousness. The quantitative and qualitative features of the facilitator-pedagogues were given.
\end{abstract}

Keywords: Teacher-facilitator, pedagogical activity, teaching process, pedagogue's personal qualities, empathy, pedagogical delicacy, self-improvement.

\section{Introduction}

The vision of building a new school in the 21st century should be based on developing new educational strategies and developing a person's moral values.

Changes and transformations in any human activity, including in the field of pedagogical professionalism, must start from its subject and creator. Thus, the student's morality is shaped by the morality of the teacher, knowledge by education, mastery by mastery. No modern technology of teaching and upbringing can help a teacher to carry out his/her pedagogical activity effectively if he/she is not personally and professionally ready for it (Asatryan L., Hakobyan G., Gevorgyan M., Asatryan M.,Karapetyan N., Baghdasaryan A., 2017).

Pedagogical support presents several requirements both for the teacher's pedagogical-professional competence, for his/her professional-personal qualities, and his/her ability to build relationships with students. The most important function of a facilitator-teacher is that he/she should support the student in carrying out activities, stimulate a successful process for students, facilitate the successful solution of many 
problems that the students face, help them successfully master extensive and challenging material in the classroom educational process. Be an assistant to the learner in developing personal, moral qualities, self-improvement, and scientific worldview.

In other words, everything depends on the development of basic human abilities. To be "here and now," to speak, to listen ("active listening" mode), to understand, and to act. (Romashina S.Ya., Mayer A. A., 2010)

The world-famous American pedagogue and psychologist Carl Rogers asks the following questions during his pedagogical activity:

1. First of all, the teacher's attitude towards the child's inner world. Every teacher, penetrating a child's inner world, should treat that world with care and without criticism.

2. Refers to the teacher-student relationship. Can the teacher build and maintain that relationship?

3. It is connected with revealing the interests of the child. Can the teacher identify the child's interests and try to satisfy them?

4. It refers to the child's personality's culture. In this case, is the teacher's culture sufficient to accept the new ideas born in the child?

5. Finally, the main question is whether the teacher can help his/her student to become a comprehensive, harmoniously developed person.

If the teacher can answer all these questions, he/she can become a facilitator. [3]

The facilitator is a leader, a teacher, whose primary goal is to stimulate, guide, help students find an easy way to analyze a specific issue or problem.

Facilitation/support can be accidental and unconscious or purposeful if carried out by a pedagogue-manager. Humanities psychologists K. Rogers and others have studied personality traits and pedagogical-managerial activities. K. Rogers seeks to overcome non-individual upbringing in the learning environment by addressing learners' interests, developing and fostering an individual approach in particular.

The central hypothesis of this approach is that a person can find vast resources of self-knowledge, changes in behavior, and self. Access to these resources is possible only if three conditions are met, which contribute to creating a certain facilitation psychological atmosphere. Those conditions are:

-Equal self-expression in communication, sincerity,

- Positive attitude towards others and accepting them without appreciation,

- Active empathic (emotional) listening and understanding (Shakhmatova, O. N., 2006).

In supporting the learning process, the teacher helps the learner acquire the 76 
necessary information and look for new ways to solve problems in the already known material.

"The essence and the most important feature of a pedagogue's profession is that it cannot be a profession "for me." It implies a professional activity "for others." This activity combines teacher's self-realization and students' purposeful development, where the overall level of education, upbringing, and development of students is important." (Asatryan L., Hakobyan G., Gevorgyan M., Asatryan M.,Karapetyan N., Baghdasaryan A., 2017). In this context, the teacher does not occupy the position of "instructor," but the role of "problem solver together with the learner" and transforms from the image of an authoritarian-pedagogue to a supporter-pedagogue. This promotes students' cognitive activity and interest, develops the ability to reflect, and optimizes their professional selfawareness.

\section{Materials and Methods}

The analysis of the theoretical and practical developments in the humanities in education and upbringing showed that the activity of the facilitator-pedagogue is not a particular method, but first of all, a specific direction of the person, a set of worldviews of values, life, and people.

In our opinion, to master the technology of facilitation, it is necessary to develop a sufficient level of teacher qualities, such as:

- Empathy / sensitivity /,

- Reflection, which is the process of self-knowledge of a person's mental acts and states. It is a person's activity, which is aimed at interpreting, analyzing, and drawing appropriate conclusions about one's own actions, inner states, feelings, emotions. In order for a person to be able to understand himself, to control and regulate his actions, to develop his inner world, he must have a high level of development of reflexivity. $[1,17]$

- High management culture,

- Respectfully and optimistically accept the learner who is capable of selfimprovement,

- Pedagogical delicacy based on trust without tolerance, ease of communication without solemnity, influence without the pressure of independence, humor without ridicule,

- Creating situations of success, choosing the proper methods of encouragement, applying them at the right time, addressing the learner by name,

- Classroom atmosphere, which promotes creative activity, 
- The ability to motivate and maintain learning,

- The ability to regulate communication with each student and group,

- The objectivity of the assessment of learners' activities,

- Ability to resolve disputes and conflicts fairly,

- Response culture.

The main difficulty is that the phenomenon of facilitation does not appear suddenly. The teacher's self-development and self-education precede it. The transition of a traditionally working teacher to such a new style is gradual, as it is associated with the slow reorganization of both himself/herself and the students. Therefore, the leaders are not so much the changes in the content and methods of teaching, but the formation and strengthening of the basic personal attitude, the constant professional growth of the teacher-educator (2016).

In the interpersonal interaction of educational subjects, pedagogues, and students, conditions are created to develop educational-professional motivation, which gives a cooperative nature to education. The current situation modernizes the need to study the conditions of optimal professional development of the person and develop technologies that positively impact the process. In addition to traditional forms and methods, personal development education envisages the use of developmental technologies: lectures on dialogue, modeling of professional situations, practical games, game exercises, training. The facilitator-pedagogue plays an essential role in the implementation of these technologies. There is a need for a pedagogue to take a new position to become a pedagogue-facilitator during their performance (Shakhmatova, O. N., 2006).

Thus, if we apply this hypothesis to the educational process, in order to activate the development of the person, it is necessary to create a special psychological atmosphere.

It should be noted that the facilitated pedagogical interaction has both the pedagogues on the students and the students on the pedagogue. Domestic researchers (E. N. Gusinsky, E. F. Zeer, L. N. Kulikova, A. B. Orlov, V. N. Smirnov, etc.) believed in Rogers' theory when defining the facilitation-pedagogical interaction. Pedagogical facilitation as a process aims to strengthen and lighten the effectiveness of education, teaching, and upbringing. The development of the subjects of pedagogical interaction is at the expense of the peculiarities of the learner and the pedagogue and their communication styleThe teacher-facilitator (supervisor) is a pedagogue whose presence and influence facilitates students' initiative, independence, supports their psychological development, and ensures positive interpersonal interaction (Shakhmatova, O. N., 2006). 


\section{Research question}

To find out how the image of the facilitator-teacher is perceived in the students' consciousness, we conducted research in which 60 students of 8-9th grades of Yerevan secondary school N194 after A. Havhannisyan and 80 students of N48 high school participated.

In the first stage of the research, the peculiarities of the facilitator's perception of the person, his/her psychological perception, communication characteristics, and behavior were studied. The respondents were offered a questionnaire, which included $15 \mathrm{semi}$ open and open-ended questions, as well as an essay on the topic "The role of the pedagogue-facilitator in the student's life." The obtained results allowed to create the social-psychological portrait (image) of the pedagogue-facilitator, which was formed in the consciousness of the respondents. Given the expressions most often used in responses and essays, the facilitator is most often perceived as a pedagogue;

$\checkmark \quad$ who has a pleasant appearance, attractive voice and literate speech

$\checkmark \quad$ is able to understand learners' feelings

$\checkmark \quad$ shows an individual approach to each student

$\checkmark \quad$ treats learners with love and respect

$\checkmark \quad$ realizes pedagogical interaction as an equal with an equal

$\checkmark \quad \mathrm{He}$ is a professional in his field, is able to show its modernity and arouses students' interest in his subject.

In order to reveal the quantitative and qualitative features of the facilitatorpedagogues in the second stage of this research, the existing pedagogues of the abovementioned school were studied.

The students of the ASPU after Kh. Abovyan acted as the experts for this study. A set of methods have been developed to identify a component of pedagogues' activities, including conversation, personal questionnaires, and observations.

In order to develop the methodology of monitoring the facilitation interaction of the pedagogue with the students, we have taken as a basis the requirements formulated by K. Rogers and presented to the pedagogue-facilitator;"

- showing reliability in learners,

- assistance in formulating and refining learning goals and objectives,

- development of intrinsic motivation in learning,

- expressed empathy,

- emotional sincerity, 
- group interaction activity,

- aspiration to share experience.

The students, who were undergoing pedagogical practice in public education institutions, acted as well-trained observers-experts. The observers were positioned so that they could see the faces of the teachers and students. Observations were recorded, the collected data was included in the facilitation interaction monitoring form of the pedagogue and the learner.

The group of observation points included such indicators as "the smile, cheerful facial expression," "gloomy, and sad expressions," "richness of expression, expressiveness," "poverty of facial expressions," "kind look." "Speed that is fast enough to understand," "Speed too fast or too slow," etc.

The group of observation points includes indicators that show the tolerance of the pedagogue. For example, students 'responses: "patient listening", "impatience with students' opinions", "interrupting them", "equality", "arrogant, takes a position from above", "encourages" "does not encourage", etc.

The monitoring unit group includes indicators that characterize the pedagogue's assurance. For example, the straight position of the head - the head is lowered, "clear movements," "confusion, vague movements," "the appearance (clothes) are practical/impractical."

Pedagogical facilitation is a process of mutual interaction of subjects /pedagoguelearner/. Therefore, elements can be emphasized in the students' actions that were also taken into account during the research. Factors such as students' activity, initiative, external interest in the lesson, activation of thinking, realization of creative potential were emphasized.

\section{Results}

Due to the observation method, significant and interesting results were obtained, which expressed the peculiarities of facilitation. We have conventionally defined three levels of facilitation for pedagogues: high, medium, and low. (Figure 1.)

Figure 1. 


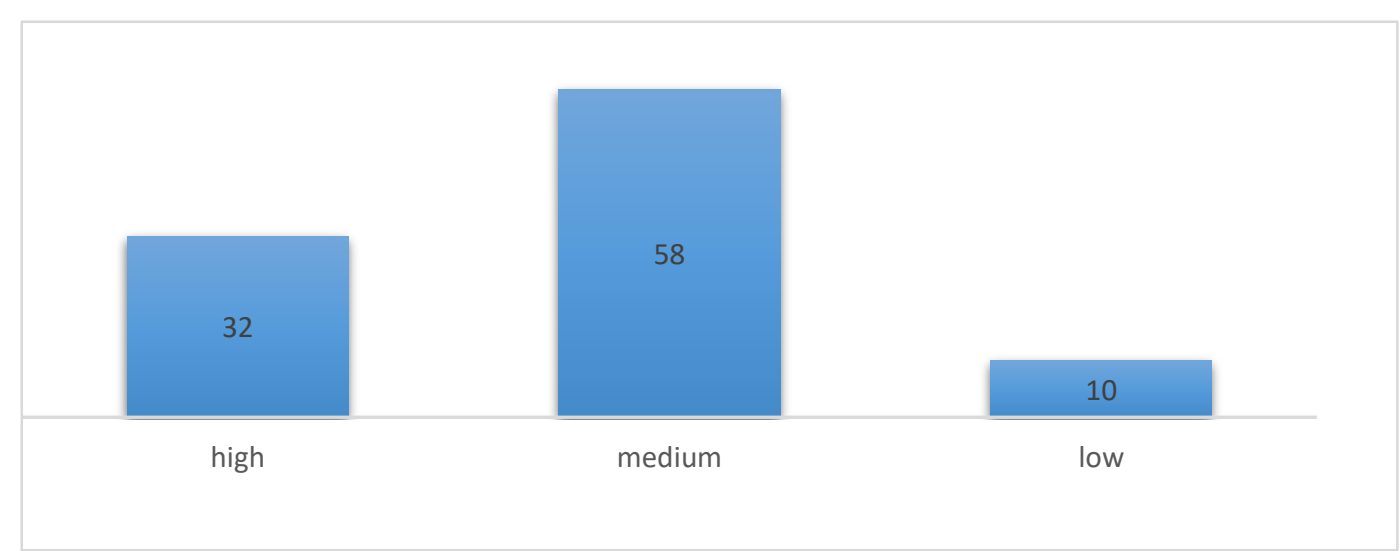

Thus, we came to the conclusion that the pedagogue-facilitators were a small percentage in the scope of our research, only $32 \%$. The pedagogue-facilitator has the following characteristics:

$\checkmark$ The pedagogue-facilitator has a posture appropriate to the pedagogue, a cheerful facial expression, a clear and literate word,

$\checkmark$ The pedagogue-facilitator openly expresses his / her feelings and emotions, penetrating the child's inner world, treating that world with care and without criticism.

$\checkmark$ The pedagogue-facilitator interacts with the students, and there is mutual understanding and cooperation between the students.

$\checkmark$ The pedagogue-facilitator supports the normalization of interpersonal relations between the students.

$\checkmark$ The pedagogue-facilitator develops critical thinking in the students, is interested in the learner's point of view, at the same time does not assert his/her point of view.

$\checkmark$ In the work of a pedagogue-facilitator, each subject of communication is recognized as a unique person.

$\checkmark$ The pedagogue-facilitator is attentive to all students.

$\checkmark$ The pedagogue-facilitator allows students to establish visual contact freely, provides feedback.

$58 \%$ of pedagogues have an average level of pedagogical facilitation. These educators do not interact with students, or they interact only at some point. They mainly interact with individual students and not with groups of students. The profession of the pedagogue (a teacher) is just a job for them. Emotional expressions are foreign to these educators, and they do not show a high level of reflection.

$10 \%$ of pedagogues revealed a low level of pedagogical facilitation. This pedagogue listens only to himself/herself, shows almost no emotions towards others, 
does not control his actions, does not treat himself/herself critically, is careless in dealing with people, is unpredictable.

\section{References}

Asatryan L., Hakobyan G., Gevorgyan M., Asatryan M.,Karapetyan N., Baghdasaryan A.. (2017). Mankavardzutyun (Pedagogy). Artagers. 360p.

I. (2016, March 6). Fasilitaciya - vedushchaya kompetenciya sovremennogo pedagoga (Facilitation is the leading competence of a modern teacher). Infourok. https://infourok.ru/fasilitaciya-veduschaya-kompetenciyasovremennogo-pedagoga-932601.html

Rogers, K.(1987). Questions I would ask myself if I were a teacher// Family and school. №11.

Romashina S.Ya., Mayer A. A. (2010). Pedagogical Facilitation: Essence and Ways of Implementation in Education: Textbook. allowance. M .: Vita-Press, 63 p.

Shakhmatova, O. N. (2006). Pedagogical Facilitation: Features of Formation and Development / O.N.Shakhmatova // Scientific research in education. - No. 3. - S. $118-125$.

Tatarenkova I.A., Kibets V.N. (2015). The teacher as a facilitator of the innovative educational process in the university// Modern problems of science and education. - No.1-1 